\title{
Regenerative Fuel Cell Power Systems for Lunar and Martian Surface Exploration
}

\author{
Monica C. Guzik ${ }^{1}$, Ian J. Jakupca ${ }^{2}$, Ryan P. Gilligan ${ }^{3}$, William R. Bennett ${ }^{4}$, Phillip J. Smith ${ }^{5}$, and James Fincannon ${ }^{6}$ \\ National Aeronautics and Space Administration, John H. Glenn Research Center, Cleveland, OH, 44135
}

This paper presents the preliminary results of a recent National Aeronautics and Space Administration (NASA) study funded under the Advanced Exploration Systems (AES) Modular Power Systems (AMPS) project. This study evaluated multiple surface locations on both the Moon and Mars, with the goal of establishing a common approach towards technology development and system design for surface power systems that use Regenerative Fuel Cell (RFC) energy storage methods. One RFC design may not be applicable to all surface locations; however, AMPS seeks to find a unified architecture, or series of architectures, that leverages a single development approach to answer the technology need for RFC systems. Early system trades were performed to select the most effective fuel cell and electrolyzer architectures based on current state-of-the-art technology, whereas later trades will establish a detailed system design to enable a near-term ground (non-flight) demonstration. This paper focuses on the initial trade studies, presents the selected fuel cell and electrolyzer architectures for follow-on system design studies, and suggests areas for further technology investment.

\section{Nomenclature}

$\begin{array}{ll}\text { AES } & =\text { Advanced Exploration Systems } \\ \text { AMPS } & =\text { AES Modular Power Systems } \\ b & =\text { Tafel-region coefficient, } \mathrm{V} \\ b & =\text { Tafel-region coefficient, } \mathrm{V} \\ \text { COTS } & =\text { commercial-off-the-shelf } \\ \text { DC } & =\text { direct current } \\ E & =\text { cell potential, } \mathrm{V} \\ \text { Eo } & =\text { open-circuit cell potential, } \mathrm{V} \\ \text { GDL } & =\text { gas diffusion layer } \\ \text { HOR } & =\text { hydrogen oxidation reaction } \\ i & =\text { operating current density, } \mathrm{mA} / \mathrm{cm}^{2} \\ i_{\text {Lim }} & =\text { limiting current density, mA/cm }{ }^{2} \\ i_{\text {offset }} & =\text { apparent reactant crossover rate, } \mathrm{mA} / \mathrm{cm}^{2} \\ I & =\text { total cell current, A } \\ \text { ISRU } & =\text { in-situ resource utilization } \\ \text { MEA } & =\text { membrane electrode assembly } \\ \text { MOXIE } & =\text { Mars Oxygen ISRU Experiment } \\ \text { ORR } & =\text { oxygen reduction reaction } \\ \text { PEM } & =\text { polymer electrolyte membrane } \\ \text { PMAD } & =\text { power management and distribution } \\ \text { PV } & =\text { photovoltaic array } \\ Q_{g e n} & =\text { total cell heat generation } \\ & \end{array}$

${ }^{1}$ Gas and Fluid Systems, Fluid and Cryogenic Systems Branch

${ }^{2}$ Direct Energy Conversion, Photovoltaic and Electrochemical Systems Branch, AIAA Member

${ }^{3}$ Gas and Fluid Systems, Fluid and Cryogenic Systems Branch

${ }^{4}$ Direct Energy Conversion, Photovoltaic and Electrochemical Systems Branch

${ }^{5}$ Direct Energy Conversion, Photovoltaic and Electrochemical Systems Branch

${ }^{6}$ Electrical Power Systems, Power Architecture and Analysis Branch 


$\begin{array}{ll}R & =\text { ohmic resistance, } \mathrm{ohm} \cdot \mathrm{cm}^{2} \\ \text { RFC } & =\text { regenerative fuel cell } \\ \text { SAWS } & =\text { Solar Array with Storage } \\ \text { STMD } & =\text { Space Technology Mission Directorate } \\ V_{t h} & =\text { thermo-neutral voltage, } \mathrm{V}\end{array}$

\section{Introduction}

S the National Aeronautics and Space Administration (NASA) continues to define its goals for exploration beyond Earth, the need persists for consistent and reliable power systems to meet the demand of both manned and large-scale robotic missions. A leading primary energy source under consideration is solar array (photovoltaic) power systems. For both the Moon and Mars, solar power is readily available during diurnal hours. However, an alternate method must be used during nocturnal hours when solar energy is not accessible. One common architectural solution is to oversize solar arrays to provide excess power that can be stored when sunlight is available during the diurnal period. This stored energy can then be expended during the nocturnal period, thereby maintaining an uninterrupted supply of primary power to the surface systems. For short durations, batteries provide the lowest overall mass and complexity for surface power systems. However, longer discharge periods with higher energy storage requirements render the battery mass penalty prohibitive, necessitating an alternative energy storage method. A regenerative fuel cell (RFC) is one method of energy storage that becomes increasingly attractive as energy storage capacity and duration requirements increase. This separates the energy conversion elements of the power system from the energy storage elements, thereby enabling independent sizing of energy conversion (power) and energy capacity (storage). Additionally, it stores energy in the form of reactant gases and water - all fluids that are readily stored in large quantities. During daylight hours, the RFC system recharges by utilizing water electrolysis to dissociate liquid water into gaseous hydrogen and oxygen. These gaseous reactants are stored for the later RFC system discharge when a fuel cell generates power and product water during the eclipse period. The product water can then be recycled to provide source water for the electrolysis system once solar energy becomes available.

NASA has extensive experience in evaluating RFC systems for surface exploration of both the Moon and Mars. Past studies ${ }^{1-6}$ indicated that the lunar energy storage requirements in particular mandate RFC energy storage as an enabling technology for solar-based power systems, largely due to the extended nocturnal periods up to nearly 360 hours where solar energy is unavailable. Although the shorter nocturnal periods of 12-13 hours for Martian surface systems have relatively short energy storage requirements compared to the Moon, other considerations have made RFC technologies of increasing interest to NASA for applications on Mars. These considerations include the use of reactants sourced from in-situ resource utilization (ISRU) integrated with lander and ascent vehicle propulsion as well as the potential to interface with human life support systems to supply water and oxygen.

To support NASA's Journey to Mars mission goals, a surface power system must be ready for flight by the mid$2030 s^{7}$. Development of this system should begin by 2025 to allow for sufficient time in the engineering design, manufacturing, and qualification testing ${ }^{8}$. Therefore, the technology development and architecture definition needs to occur as soon as possible to meet the current NASA mission targets. In 2016, the NASA Advanced Exploration Systems (AES) Modular Power Systems (AMPS) project was tasked with evaluating various RFC system architectures to meet various Martian and lunar surface system requirements. The AMPS team actively collaborated with the NASA Space Technology Mission Directorate (STMD)-sponsored Solar Array with Storage (SAWS) study to investigate RFC systems for Martian surface power, and leveraged previous work to incorporate lunar missions into the trade space. The study considers a stand-alone, independent RFC surface power system as an initial trade space to simplify the initial modeling effort. Forward work to incorporate integration with other surface systems is required to facilitate a final technology selection. A second goal of the study was to identify a system for a near-term technology demonstration based on the current state of the art hardware as well as recognize areas that require further development. This approach would allow a reduced cost demonstration of a flight-relevant RFC system well in advance of the 2025 need date, yet still permit technology investment in key areas to enhance overall performance as technologies mature.

While multiple electrolysis technologies exist, Proton Exchange Membrane (PEM) electrolysis was selected for this study due to the relatively high technical readiness and ability to operate over a wide range of pressures and flow conditions. The ceramic electrode in a solid oxide electrolyzer is relatively impervious to absolute pressure but very sensitive to differential pressures, especially for larger active areas. More importantly, the mechanical seals of the cells and manifolds are not yet sufficient to operate a solid oxide electrolyzer at any meaningful pressure at a relevant scale for surface power applications. Solid oxide electrolyzer technology is being demonstrated by the Mars Oxygen ISRU Experiment (MOXIE) in an upcoming flight experiment for the Mars 2020 mission?. The MOXIE 
demonstration experiment has generated successful results on a very small scale, which encourages the possibility of eventually developing a solution to this seal limitation. The very low pressures of solid oxide electrolyzers require additional hardware to pressurize the product gases from discharge pressure to the final gas storage pressure. Early comparisons of various pressurization methods showed that electrochemical pressurization is more efficient than mechanical pressurization. In addition, mechanical compression is achieved external to the electrochemical stack, thereby adding system mass and complexity while reducing overall reliability. At the time of publishing, PEM electrolysis is the only electrochemical technology that has demonstrated reliable high-pressure operation at a relevant scale. Therefore, only PEM electrolysis was considered for this trade study. Further development of solid oxide electrolysis technology for high-pressure operation may require an update to this approach.

Initial trades focused on pairing a PEM electrolysis stack with one of two fuel cell chemistries: low-temperature PEM fuel cells, which create liquid water, and high-temperature solid oxide fuel cells, which create steam. The initial trades informed a selection of the appropriate technology that best satisfies the widest array of energy storage requirements for surface missions. These initial trades utilized a common approach for the subsystems required for electrolyzer and fuel cell integration, such as reactant storage and thermal control. Follow-on trades are underway to evaluate the integrated system components that would result in the lowest mass, lowest volume, highest reliability, and highest efficiency system that is extensible to multiple locations. This paper presents the methods and results behind the initial trade studies and provides suggested areas for further technology development investment.

\section{Mission Locations}

Locations on the Lunar and Martian surfaces were considered as bounding criteria for length of day/night cycles, solar proximity, and relevance to previous or existing NASA missions. Four Lunar locations were considered, with two selected as the primary bounding cases for initial trade studies ${ }^{10,11}$. The mission with the highest energy storage requirement, a lunar equatorial location with a 356 hour eclipse period, provides the upper energy storage boundary. This location applies to lunar latitudes from -70 degrees to +70 degrees at any longitude with minimal requirement changes. Other locations considered included the Whipple Crater at the Lunar North Pole, the Shackleton Crater at the Lunar South Pole, and a lunar mid-latitude location at 45 degrees that reflects a deviation in thermal environment and solar array design for non-equatorial bases. Of these, the Shackleton Crater at the Lunar South Pole was selected, as it has the minimum energy storage requirements for a lunar location and the longest daylight duration. This location also is the most sensitive to operational concepts for the RFC, and offers the highest amount of flexibility in determining operational efficiency. For the Lunar South Pole, the electrolysis stacks were operated for a fraction of the daylight time. This duration was varied for each run to maintain the PV charge power required at or below $20 \mathrm{~kW}$, and was typically around $12-14 \%$ of the total daylight period.

Along with the lunar surface locations, three Martian locations were considered ${ }^{1}$. The Jezero Crater, a Martian mid-latitude location at 18 degrees north, was selected as having the lower energy storage boundary, as it boasts the shortest eclipse period, at 13.5 hours. This site was an early candidate for the Mars Science Laboratory and is under consideration for the Mars 2020 mission. A Martian equatorial site, analogous to the Opportunity rover location, was selected for the large amount of data that exists for that location, the favorable night durations, and the minimal seasonal variations. Finally, the Columbus Crater, a Martian mid-latitude location at 30 degrees south, was considered but not included in the study due to the highly variable weather and seasonal conditions. These transient conditions rendered the steady state input solar power assumptions unusable, and so this location was excluded from the scope of the initial trade studies. In total, two Martian locations and two lunar locations were chosen for the initial trades to facilitate an early down select for the RFC architecture, as shown in Table 1. Note that for each of the locations, PEM electrolyzers were paired with either PEM fuel cells or solid oxide fuel cells, resulting in eight formal trades to frame the RFC architecture design study.

Table 1. Selected Sites for Initial RFC Architecture Trade Studies

\begin{tabular}{|l|c|c|c|}
\hline Surface & Location & Night/Eclipse Duration & Daylight Duration \\
\hline Mars & Equator & 13.5 hours & 11.2 hours \\
Mars & Mid Latitude (Jezero Crater) & 12.3 hours & 12.3 hours \\
Moon & Equator & 356 hours & 354 hours \\
Moon & South Pole (Shackleton Crater) & 73.0 hours & 637 hours \\
\hline
\end{tabular}




\section{Study Approach}

Selection of a unified RFC architecture that optimally satisfies a variety of mission requirements was complicated by the complex interface requirements within an RFC system, as well as the large differences in energy storage requirements for each mission. In an attempt to simplify the effort, a three-step process, shown in Figure 1, was formulated for the analysis and evaluation of various technologies for implementation into an RFC system. First, customer needs were surveyed across various mission locations (block 1). From this survey, four mission locations were selected to capture the broadest range of mission requirements for surface power applications (block 2), as described in Section III. Next, an Excel-based model was developed to allow high-level trades between various fuel cell technologies while interfacing with a PEM electrolyzer (block 3). These high-level trades allowed for the selection of a single technology architecture approach based on the current state of the art technology available that best matches a wide range of surface mission locations (block 4). The results from these trades also identified further areas for technology development with the potential to advance the RFC technology towards a state of readiness for future NASA missions (block 5). The final steps in the study process were to evaluate and select the detailed system design and component selection that best matched the selected architecture for a potential near-term ground demonstration (blocks 6 and 7). These final steps have been initiated but not completed at the time of publishing for this paper.

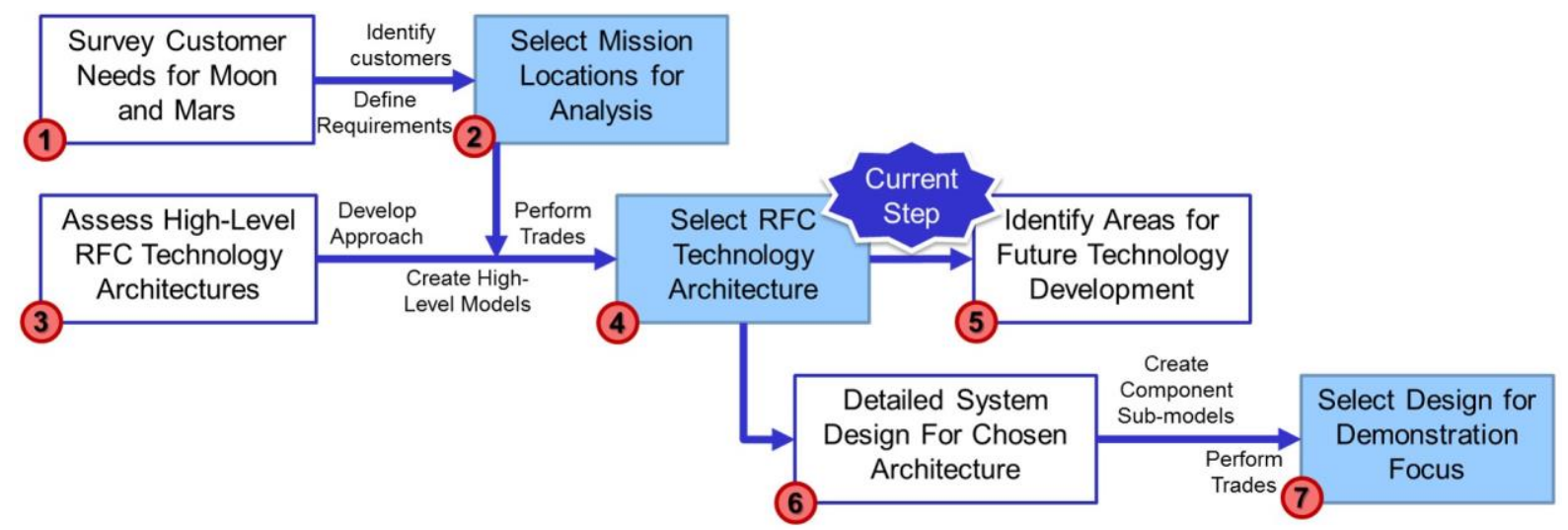

Figure 1. RFC Architecture Trade Study Approach. The RFC architecture trade study utilized a three-tiered process, with deliverables shown in the blue highlighted boxes. The sequence of events follows the diagram from left to right.

To facilitate the comparison between multiple fuel cell and electrolyzer technologies when integrated into a single RFC system, several simplifying assumptions were made. First, the mass and power penalties incurred by the customer power management and distribution (PMAD) system as well as that of the solar array system providing primary power were not included in the study. Instead, the net power required from the solar array for electrolysis and other RFC-specific operations during daylight cycle was used as a performance metric to account for the additional solar array structure and area required. The study utilized a steady state model, with a direct step change in power demand between day and night cycles. No effort was taken to account for a ramped or gradual transition in the power profile of the system due to the wide range in solar output the results from diurnal, orbital, and seasonal variability ${ }^{12,13}$. Additionally, the model did not address component reliability except for the electrochemical stacks and the reactant storage tanks. All other subsystems were modeled using the same approach for both fuel cell technologies, and so the inclusion of a reliability analysis on these systems was not deemed necessary for the initial trades. To include redundancy, three fuel cell stacks were sized to run in parallel, with the ability to meet power requirements in the event of a single stack failure. This redundancy approach was duplicated for the electrolysis stacks, but not repeated for any other component. A single approach for reactant storage and thermal system calculations was used for all technologies, although variations were made to account for differences in operational temperatures and storage durations, as described in Section VI.

Four performance metrics were chosen to evaluate the various technologies for each mission location as shown in Table 2. The first metric was the RFC system mass, defined as the sum of all component masses for the support structure, enclosure, thermal control system, fuel cell stacks, electrolysis stacks, and reactant storage hardware, including fluid handling. RFC system volume was defined as the sum of the volumes of the fuel cell stacks, electrolysis stacks, coolant tank, and any heat exchangers with a packing factor of three applied as a multiplier to account for ancillary hardware and packaging volumetric inefficiencies. The volume of the reactant storage tanks 
and radiator were then added to give a total RFC system volume. Photovoltaic array (PV) charge power required was the sum of the input power needed for fuel cell keep-alive power, other parasitic power for ancillary hardware such as pumps and valves, and the input power needed for electrolysis to generate sufficient reactant for fuel cell operation. Finally, specific energy was defined as the total energy produced by the fuel cell stacks, including that needed to accommodate parasitic power from the RFC hardware, divided by the total RFC system mass. These metrics were used as the primary points of comparison between fuel cell technology architectures. For all cases, system sizing was based on providing a net power output of $10 \mathrm{~kW}$ to the mission customer, not accounting for transmission line losses or PMAD inefficiencies. Over the 12-earth-year operational life considered by this trade study for all mission locations, the system was required to complete as many as 4,270 charge-discharge cycles. This places an operational life of $>46,000$ electrolysis hours and $>60,000$ fuel cell hours, depending on the mission location. While this initial trade did not specifically address reliability, this long life requirement necessitates a focused forward effort on establishing system-level reliability and long duration operations.

Table 2. RFC Trade Study Performance Metrics with Weight Factors

\begin{tabular}{|l|c|}
\hline \multicolumn{1}{|c|}{ Performance Metric } & Weight Factor \\
\hline RFC System Mass & 0.50 \\
\hline RFC System Volume & 0.25 \\
\hline Photovoltaic (PV) Charge Power Required & 1.0 \\
\hline Specific Energy & 0.50 \\
\hline
\end{tabular}

\section{RFC System Modeling Approach}

\section{A. Fuel Cell Modeling Approach}

A fuel cell stack is a type of flow battery. As an energy conversion device, it converts the chemical energy of the reactants into direct current (DC) electrical energy. This is not a perfectly efficient process, so the input reactants generate byproduct chemicals and heat with the electricity. Rather than relying on dissolved or suspended reactants in a carrier fluid to source the potential chemical energy, the fuel cells under consideration for this study utilize hydrogen and oxygen gases as both carrier fluids and sources for the chemical energy. This simplifies the support fluidic and electronic hardware systems required to support the chemical reaction.

Since a fuel cell is an energy conversion device, it cannot store energy. Thus, energy storage metrics do not apply to a fuel cell stack of any chemistry. This is a critical difference between a battery and a fuel cell, as the size of the fuel cell stack only depends on the required stack life, output current, and operational voltage. A fuel cell is a current-generating device with a voltage resulting from the efficiency of the reaction. Each individual cell generates between 0.65 and $1.1 \mathrm{Vdc}$ during operation, depending on the current. To satisfy the stack voltage requirement, additional cells can be installed in series to increase the net output voltage of the stack. To satisfy the output power requirements, a design current density is selected to determine the active area of the cell. The active area is defined as the surface area in contact with the bulk fluid, where the chemical conversion process occurs. The current density is the bulk electrical current flowing through the cell divided by the active area of the cell. The potential operational current density depends on the fuel cell chemistry, anticipated life, electrical load profile, and stack construction. An increase in the required operational life causes a decrease in the selected current density, with a minimum current density determined by the specific stack chemistry and construction. PEM fuel cell stacks operating solely on gaseous hydrogen and oxygen have sustained current densities ranging in excess of $1,000 \mathrm{~mA} / \mathrm{cm}^{2}$ and SOFC stacks operating on gaseous hydrogen and oxygen have current densities below $500 \mathrm{~mA} / \mathrm{cm}^{2}$. When specific application requirements are known, values that are more precise are available from hardware vendors.

A PEM fuel cell uses a Nafion ${ }^{\mathrm{TM}}$-based polymeric membrane as the core of the membrane electrode assembly (MEA), which comprises the functional element of a single cell. Within the active area of the membrane, a reactionspecific catalyst is applied to each side of the membrane on a supporting structure. The cathode side utilizes catalysts that facilitate the oxygen reduction reaction, which reduces the oxygen gas molecule into liquid water. The catalysts on the anode facilitate the hydrogen oxidation reaction, which oxidizes the hydrogen and strips electrons from the hydrogen gas molecule to produce two protons. Nafion ${ }^{\mathrm{TM}}$ is an electrically insulating cation conductor, so the hydrogen protons are transported through the Nafion ${ }^{\mathrm{TM}}$ membrane from the anode to the cathode. The electrons generated are electrically conducted through the bipolar plate to the cathode of the adjacent cell, where they form liquid water in the oxygen reduction reaction. The product water must be removed from the catalyst surface for the reaction to perpetuate. The MEA has an operational temperature range limited by Nafion ${ }^{\mathrm{TM}}$ to between $4^{\circ} \mathrm{C}$ and $85^{\circ} \mathrm{C}$ due its liquid-water component. 
A solid oxide fuel cell uses an electrically insulating anionic conducting ceramic. The solid oxide fuel cell conducts oxygen anions through the ceramic plate via diffusive processes requiring temperatures between $600^{\circ} \mathrm{C}$ and $1,000^{\circ} \mathrm{C}$. In the solid oxide fuel cell, the oxygen is reduced in the cathode to generate oxygen anions. These anions traverse the ceramic electrode to oxidize the hydrogen fuel into water at the anode. Electrons released by the oxidation of hydrogen are conducted by the cell interconnects to the adjacent cell to reduce the gaseous oxygen into anions. Since the product water vapor can suppress the overall reaction, it needs to be removed from the cell. Additional fuel is flowed through the anode to remove the water vapor from the stack and perpetuate the reaction.

Due to the high temperatures and chemically aggressive environment, sealing issues must be addressed in the solid oxide fuel cell system design. In terrestrial solid oxide fuel cell stacks, the seals are allowed to leak so the fuel mixes with the oxidizer and combusts, thereby helping to maintain the stack at its optimal operating temperature. This combustion occurs near the seals and within the thermally insulating furnace that is required to maintain the stack temperature. The amount of reactant lost to combustion directly affects reactant utilization. For surface power applications, a trade between thermal control and reactant utilization must be considered. For the purposes of this trade, this trade was circumvented by placing the entire solid oxide fuel cell stack and furnace within a hermetically sealed enclosure to prevent significant losses of hydrogen to the environment over the multi-year operation while also maintaining the thermal control advantages of the leaking seals.

Fuel cell voltage for both the PEM and solid oxide fuel cells was modeled as a function of current density, $i$, using a semi-empirical formula shown in Eq. (1).

$$
E=E_{0}+b \cdot \ln \left(i+i_{\text {offset }}\right)+i R+c \cdot \ln \left(1-i / i_{\text {Lim }}\right)
$$

Equation (1) uses parameters that have physical significance, and reliably fits cell voltage over the entire range of current density. Parameters were fitted to test data collected for a variety of fuel cells tested under relevant conditions of temperature and pressure. This equation includes terms for the low current density Tafel region, the ohmic region, and the mass transfer limited region at high current density. The term, $i_{\text {offset }}$, was included to describe cell voltage at very low current density. This term captures the cell polarization that occurs due to reactant crossover at open-circuit. Parameter fitting was performed using data at known operating pressure. Adjustment to the cell voltage for change in pressure was made using the Nernst equation ${ }^{14}$.

Heat generation was projected by multiplying the difference between the thermo-neutral voltage, $V_{t h}$, and the projected operating cell voltage, $E$., by the total cell current, $I$.

$$
\mathrm{Q}_{\mathrm{gen}}=I\left(V_{t h}-E\right)
$$

In Eq. (2), the difference between the thermo-neutral voltage and the actual observed cell voltage represents the total shortfall in useful work achieved by the cell. This simple expression includes reversible (entropic) and irreversible (ohmic) heat sources in the cell ${ }^{15-17}$. In this work, thermo-neutral voltage was calculated from the enthalpy change for the fuel cell reaction, $\mathrm{H}_{2}+1 / 2 \mathrm{O}_{2}=\mathrm{H}_{2} \mathrm{O}$, using tabulated thermodynamic properties. Effect of pressure on enthalpy was expected to be negligible over the pressure range explored in this trade study ${ }^{18}$. The model was constructed so that it was independent of fuel cell chemistry as much as possible. The primary differences result from the thermal differences between the two chemistries, as discussed in Sections IV-C and IV-D. Figure 2 illustrates the differences in fluidic design between the two stack types. 


\section{$\underline{\text { PEMFC }}$}

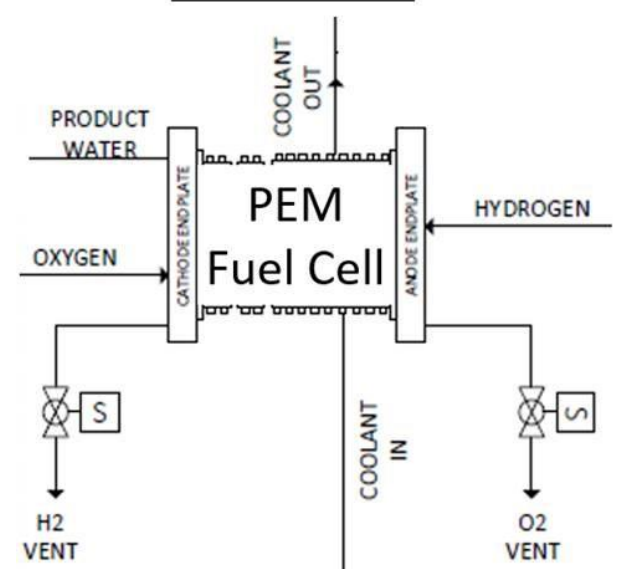

$\underline{\text { SOFC }}$

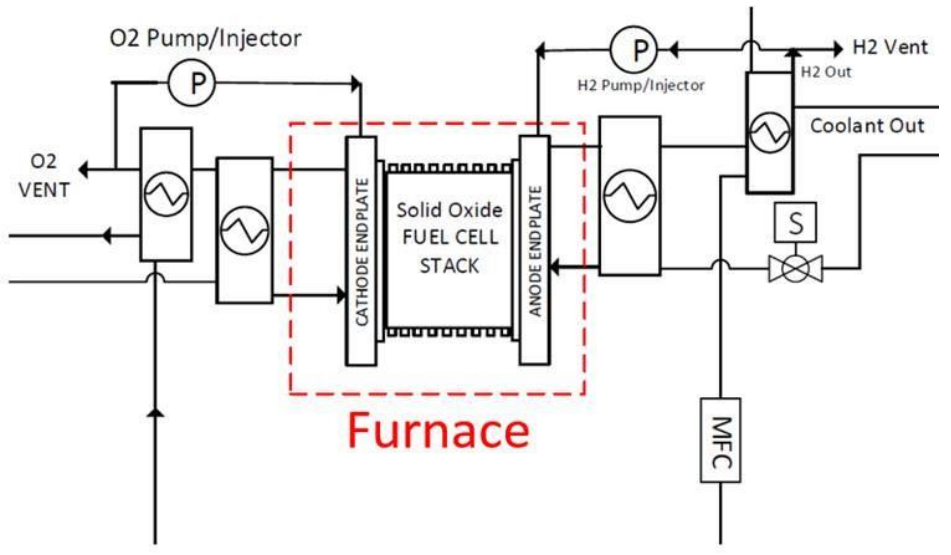

Figure 2. PEM Fuel Cell (PEMFC) and Solid Oxide Fuel Cell (SOFC) Fluidic Design Schematics. The PEMFC hardware specific to PEMFC functions in an RFC system are shown on the left. The SOFC hardware, including a furnace and additional heat exchangers, are shown on the right.

\section{B. Electrolysis Modeling Approach}

For this application, electrolysis dissociates water by providing electrical energy to break the covalent bond between the hydrogen and oxygen atoms within the water molecule and ensure the charge balance of the resulting hydrogen and oxygen molecules. While strongly influenced by temperature, the chemical process is relatively insensitive to pressure. Hydrogen is a moderately strong reducing agent and oxygen is a very strong oxidizing agent. The reactivity of these fluids are positively influenced by pressure, thus requiring very careful component selection and system design to minimize hazardous situations. In an energy storage application, the storage pressure of the reactant gases strongly influences the mass and volume of the system. This creates opposing design constraints as safety and efficiency considerations drive towards a low-pressure design whereas energy density and volume optimization both favor a high-pressure design.

PEM electrolysis hardware has operated at high pressures in excess of 2,000 psi for decades. The technology is well understood for military, commercial, and industrial applications. More development remains necessary to achieve the high pressures and conversion rates required by aerospace applications. One inefficiency element of PEM electrolysis is the back-diffusion of reactants driven by the species and pressure gradients across the polymeric membrane. This loss is heavily dependent on MEA and stack design. For the purposes of this study, pressures were limited to be less than 3,000 psi. Operating at higher pressures complicates the wetted material selection and the internal design of components.

Modeling of PEM electrolyzer performance was analogous to the PEM fuel cell. Cell voltage was predicted using the same form of equations for fuel cell polarization and heat generation. Equation (1) parameters were fitted to test data for relevant PEM electrolysis stacks. Inefficiencies due to gas crossover were estimated using data ${ }^{5}$ for gas permeability in humidified Nafion ${ }^{\mathrm{TM}}$. Three types of PEM electrolysis were considered for this study: Anode liquid feed, cathode liquid feed, and cathode vapor feed. Anode liquid feed uses the least amount of power per unit of water electrolyzed, and cathode vapor feed has the highest cell power requirement. Figure 3 contrasts the relative current density that is supported at a given cell voltage for these electrolysis approaches. The curves were generated using Eq. (1). 


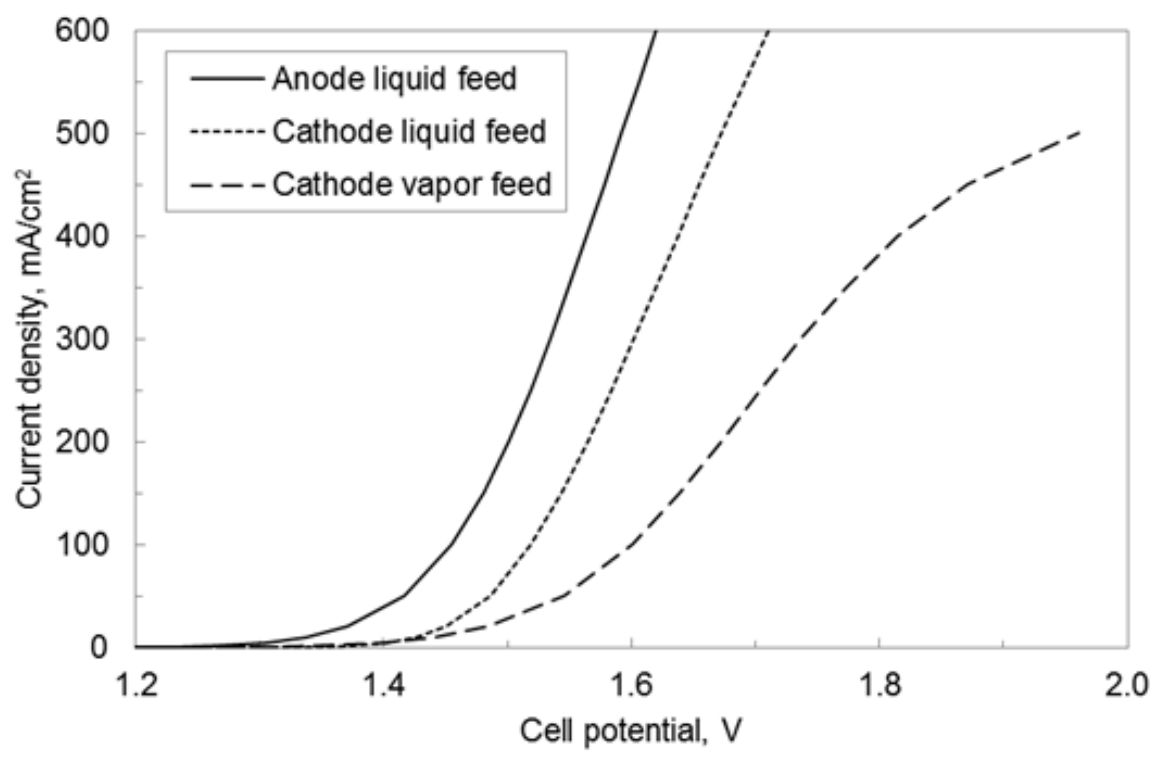

Figure 3. Current/Cell Voltage Relationship for Different Types of PEM Electrolysis. The current/cell voltage relationship for anode liquid feed PEM electrolysis is shown by the upper solid line, while the middle dotted line indicates cathode liquid feed, and the lower dashed line denotes cathode vapor feed.

Anode liquid feed was selected for the initial trade study analysis due to the higher current density that can be supported at a given cell voltage. This choice minimized the power demand of the electrolysis system, and it was expected to minimize the size and weight of the supporting photovoltaic array. A more detailed evaluation and selection of RFC electrolysis types will be addressed in future trade studies. Other considerations for selection include the effect of gas crossover and protonic drag effects ${ }^{20,21}$. These factors introduce inefficiencies to the electrolysis system and impose different levels of fluid handling, depending on the selected of PEM electrolyzer type.

\section{PEM Fuel Cell-based Thermal System Modeling}

The thermal system of the RFC had three chief requirements. The first requirement was to reject the waste heat generated by the fuel cells and the electrolyzers. The second requirement was to minimize thermal cycling of the fuel cell and electrolyzer. Cycling from the minimum allowable PEM temperature of $20^{\circ} \mathrm{C}$ to operational temperature at $60^{\circ} \mathrm{C}$ was considered unacceptable, as the resulting mechanical stress cycles could cause delamination of the polymer membrane and catalyst over the $>4,270$ cycles required by the mission ${ }^{22}$. For solid oxide fuel cells, the temperature difference between ambient and operating temperature was greater than PEM systems by roughly $700^{\circ} \mathrm{C}$. The third requirement related to keeping the liquid water in various parts of the system from freezing. For example, freezing would stress and damage the membrane electrode assembly in PEM stacks due to their high liquid water content. The coolant used in the system was deionized water, which must be maintained in a specific temperature range to prevent freezing of the fluid lines. Future design work may allow the coolant water to be integrated with the electrochemical process water, but the two fluids were kept separate in this study. No attempt was made to maintain the low resistivity required of this recirculating water, but this was identified as an area for future development.

The traditional PEM fuel cell systems used as the baseline for analysis have coolant flow passages built into the structure to allow the heat from the reaction to be uniformly removed from the stack using the liquid water coolant. The coolant system contained a coolant reservoir, pump, flow meter, various solenoid valves, mass flow controllers, and a radiator to reject the system heat to the surrounding environment ${ }^{23}$. During fuel cell operation, the coolant was routed from the pump to the fuel cell stacks, and then sent directly to the electrolyzer before running through the radiator for heat rejection. This concept allowed the waste heat produced by the fuel cell to be used to keep the PEM electrolyzer near its operational temperature while it was in a standby mode, thus satisfying the second thermal requirement of minimized thermal cycles.

To satisfy the first thermal requirement, the coolant rejected the heat generated by the RFC to an external radiator. The radiator design was based off the external DC-to-DC Conversion Unit (DDCU) heat pipe radiator used 
for the International Space Station ${ }^{24}$. The radiator consisted of a baseplate heat exchanger that transferred heat from the warm coolant to the radiator surface via heat pipes. The working fluid in the heat pipes was ammonia, which limited the baseplate temperature range from $-30^{\circ} \mathrm{C}$ to $65^{\circ} \mathrm{C}$. The maximum sink temperature for the radiator was determined by the average daytime and nighttime temperatures for each location. The nighttime sink temperature was used for the fuel cell heat rejection radiator sizing calculations, and the daytime sink temperature was used for the electrolyzer. The model selected the largest radiator size required between the electrolyzer and fuel cell heat rejection needs. The maximum baseplate temperature was the maximum fuel cell operating temperature of $60^{\circ} \mathrm{C}$. The temperature difference between the baseplate and the radiator was set at $4^{\circ} \mathrm{C}$. It was assumed that there were no obstructions between the radiator and the ambient sink environment, so the view factor was set at 1.0 for model simplicity. The color of the radiator surface was white, so the emissivity was set at 0.92 . It was assumed that a passive thermostatic valve would regulate flow to the radiator to achieve a temperature in the coolant reservoir equivalent to the coolant inlet temperature of the fuel cell. The maximum heat load generated by the PEM fuel cell stacks was $7.6 \mathrm{~kW}$ for a $10.2 \mathrm{~kW}$ net electrical power generation. The coolant flow rate was calculated by assuming a temperature differential across the fuel cell stack of $5^{\circ} \mathrm{C}$. This flow rate was used to size the pump and determine its parasitic load on the system.

To meet the third requirement of freeze prevention, a thermal barrier was established. The majority of the system, excluding the hydrogen and oxygen tanks, was enclosed within the thermal barrier as shown by the red dashed line in Figure 4. This barrier was intended to provide a stable ambient temperature around $20^{\circ} \mathrm{C}$ for the components within its boundary. The proposed concept for the barrier was a metal cylinder or dome that enclosed the fuel cell stacks, electrolyzer stacks, coolant reservoir, fluid lines, pumps, valves, and other hardware. The cylinder was insulated on the outside surface. Electric heaters inside the metal provided heat to the structure when required. In some locations, coolant lines were used to provide targeted cooling to localized hot spots. A more detailed design for maintaining the thermal boundary temperatures was identified as forward work for the next stage of modeling.

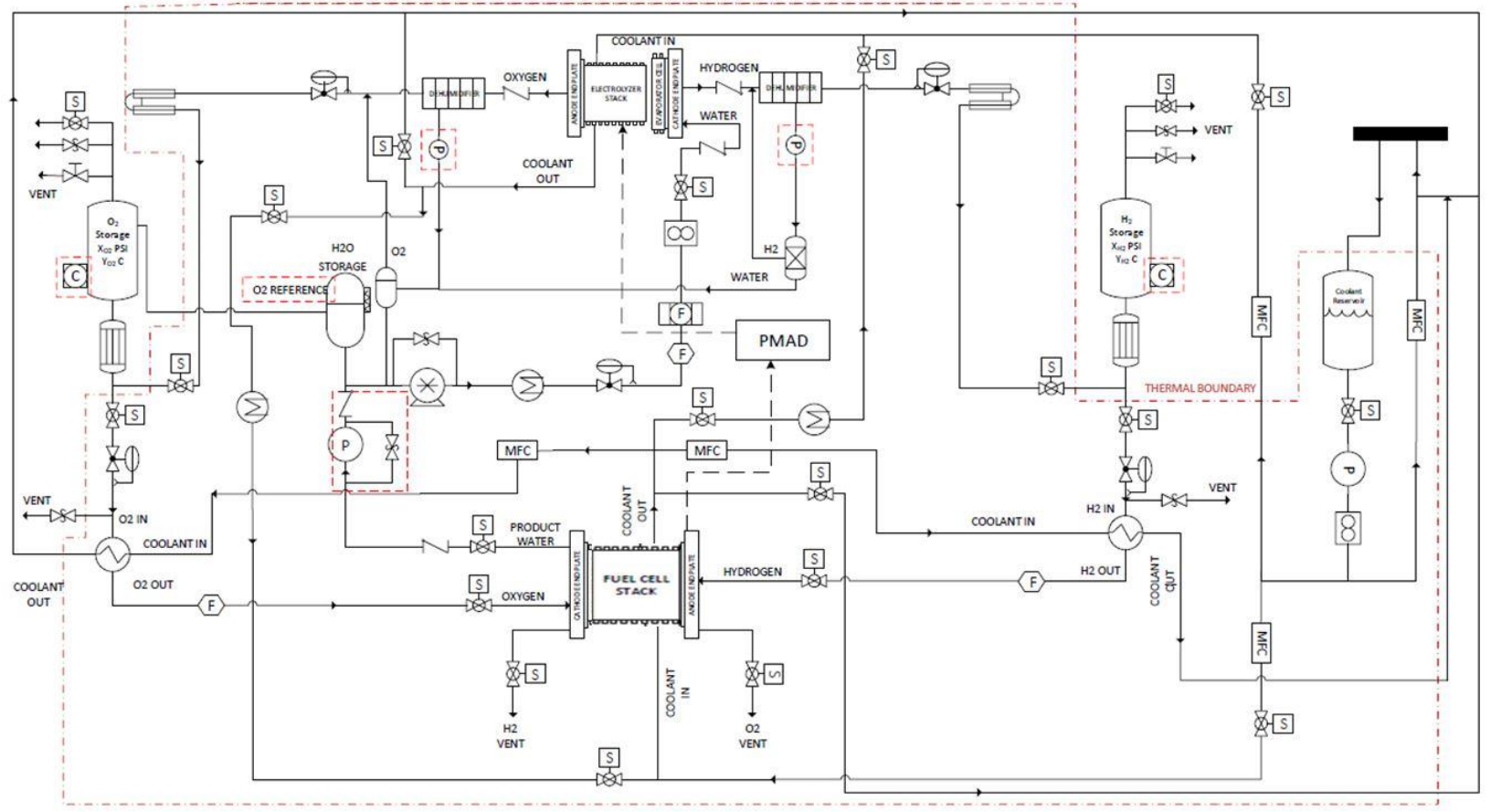

Figure 4. PEM fuel cell-based RFC Piping and Instrumentation Diagram (P\&ID). This P\&ID shows the conceptual RFC system that uses a PEM fuel cell and PEM electrolyzer. The thermal barrier is shown in the outermost dark red dotted line. The red dashed lines indicate components requiring further detailed design studies.

\section{Solid Oxide Fuel Cell-based Thermal System Modeling}

The solid oxide fuel cell reaction requires temperatures ranging from $600^{\circ} \mathrm{C}$ to $1,000^{\circ} \mathrm{C}$. Due to their high operating temperature, the electrochemical reactions of solid oxide fuel cells are more efficient than PEM fuel cells. Therefore, for a constant $10 \mathrm{~kW}$ of power generation, the solid oxide fuel cell generated less waste heat than the PEM fuel cell with a total heat rejection requirement of $3.5 \mathrm{~kW}$. Although the total heat to reject was lower for a 
solid oxide fuel cell, the high quality nature of the heat source meant that routing a liquid-water cooling loop directly through the fuel cell was impossible. The solid oxide fuel cell required four heat exchangers and two recirculating blowers to recirculate unreacted gas to remove the product water and regulate stack temperature ${ }^{23}$.

The first heat exchanger was a recuperative heat exchanger that was used to raise the temperature of the hydrogen or oxygen entering the fuel cell by using the hot unused reactant from the exit of the stack. Electrical heaters raised the inlet gas temperature at the exit of the recuperative heat exchanger to the stack operating temperature. For the solid oxide fuel cell systems, product water was generated in the hydrogen cavity as steam. The PEM electrolyzer requires liquid water to regenerate the hydrogen and oxygen reactants, so the steam exiting the solid oxide fuel cell must be condensed prior to storage. The second heat exchanger in the hydrogen system used a liquid-water cooling loop to condense the steam to liquid water for storage. The second heat exchanger in the oxygen system was used to cool the gas exit stream and remove heat generated by the system. Heat was rejected from the solid oxide fuel cell by recirculating the hydrogen and oxygen gases to remove heat from the stack and then rejected to the coolant in the second heat exchanger. The flow rate of gas required to remove the high quality heat was solved for by using a goal seek in Excel to force the heat generated by the fuel cell to equal the sum of the heat lost to the surroundings and the heat transferred in the recuperative heat exchangers. The warm deionized water leaving the second heat exchangers was then routed to the PEM electrolyzer to prevent thermal cycling. The coolant was then routed to a radiator that was sized using the same method as that used for the PEM fuel cell-based thermal system. As with the PEM-based system, a thermal boundary was erected around the RFC components as shown by the dotted line in Figure 5.

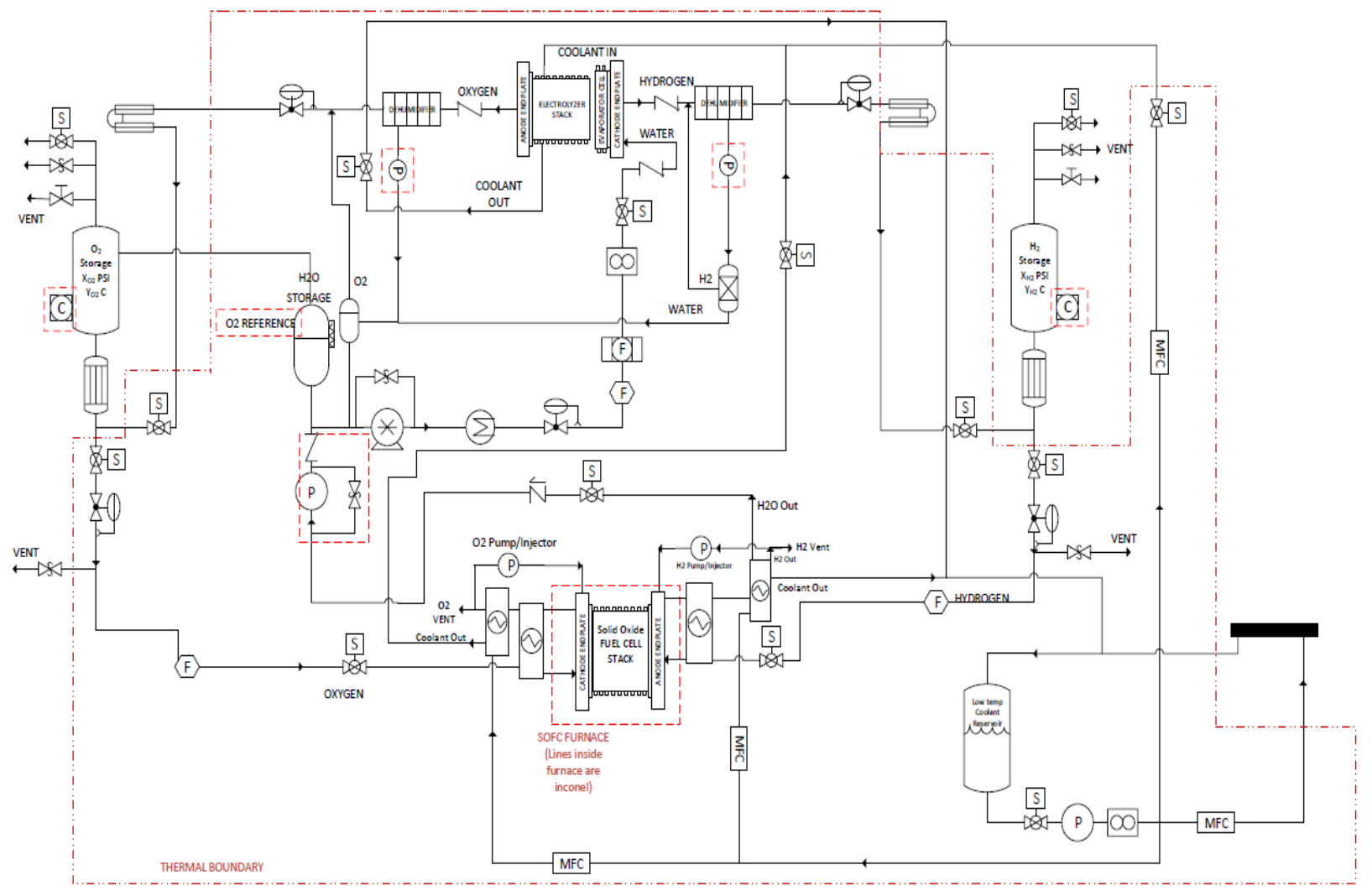

Figure 5. Solid oxide fuel cell-based RFC Piping and Instrumentation Diagram (P\&ID). This $P \& I D$ shows the conceptual RFC that uses a solid oxide fuel cell and PEM electrolyzer. The thermal barrier is shown in the outermost dark red dotted line. The red dashed lines indicate components requiring further detailed design studies.

The solid oxide fuel cells were maintained at a desired standby temperature using electric heaters evenly distributed over the fuel cell. With a temperature difference between this standby temperature and the thermal enclosure temperature of several hundred degrees Celsius, the heater power lost from the fuel cell via radiation would be prohibitively large without any insulation and could melt some of the ancillary components. To avoid this heat loss, the solid oxide fuel cell was surrounded by a furnace to provide a second thermal boundary. It also provided a sealed container to mitigate the extensive external leakage inherent in solid oxide fuel cells. The furnace consisted of high temperature insulation and a hermetically sealed metal hot box. The heat loss for a given insulation 
thickness was calculated using thermal resistances. A planar geometry for the solid oxide fuel cell was considered in this model, so it was assumed that the thickness of the insulation was uniform in each direction.

\section{E. Reactant Storage System Modeling}

The Reactant Storage System was designed using the same principles for both the PEM and solid oxide fuel cell chemistries. Maximum reactant storage requirements occurred at the end of the electrolyzer operation cycle. At that stage in RFC operation, the gas cylinders, located outside the system's thermal boundary, were assumed to be at the maximum daytime sink temperature for the chosen location. The model minimized the reactant storage mass by evaluating a list of 75 commercial-off-the-shelf (COTS) gas storage tanks. These gas cylinders ranged in internal volume from 45 to 157,000 cubic inches and met all safety and design standards for their intended commercial applications.

Based on the electrolyzer pressure capability, the lunar or Martian mission profile, the energy storage duration, and the environmental conditions, a required storage volume was calculated using the ideal gas law. Empirical gas compressibility factor adjustments were applied to the ideal gas calculation for both hydrogen and oxygen gases. The storage volume enabled calculation of the number of vessels and the resulting total mass for each COTS cylinder size while eliminating those not rated to contain the maximum storage pressure. For all trade study runs, the maximum storage pressure was set at 1500 psia. The total mass of all tank fittings, valves, and manifolds was assumed equal to $15 \%$ of the total cylinder mass. A single cylinder size was selected for each gas species.

In the both versions of the model, product water drained from the stack was stored in an insulated spherical reservoir sized to contain the maximum water quantity at the end of the fuel cell operation cycle. Excess water storage was included to accommodate hydrogen gas overboard leakage and venting and electrochemical stack inefficiencies, as well as to provide surplus chemical energy storage capacity in the case of additional photovoltaic power availability.

During electrolyzer operation, the stored water became the supply for electrolysis. It was electrically heated and then pumped to the user-designated pressure with a COTS pump. As with the thermal system pumps, this unit was selected to minimize weight and maximize efficiency from the available options within the model's COTS pump database. For the chosen anode feed electrolyzers, water exited the stack along with the generated reactants. The saturated reactant gases were dehumidified before being sent to the storage vessels and the liquid water was returned to the supply feed side of the line heaters and high-pressure pump.

Product water exited the solid oxide fuel cell as water vapor that was cooled and condensed in a series of heat exchangers to heat the incoming hydrogen, as described in Section IV-D. The water was then stored in the same manner as for the PEM fuel cell until electrolysis commenced. Figure 6 shows a simplified schematic indicating the primary interfaces in the reactant storage system. 


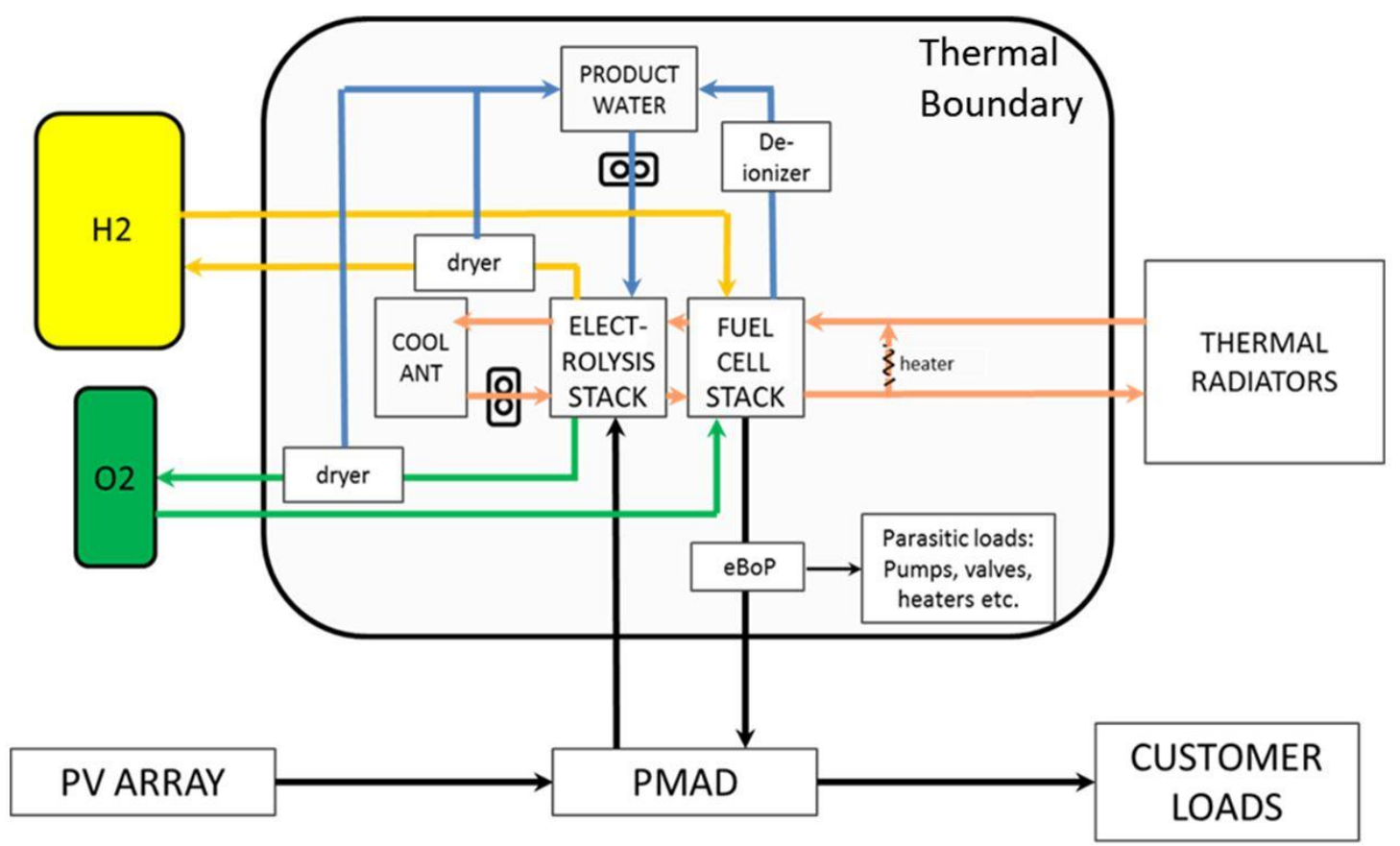

Figure 6. Simplified Interface Schematic for an RFC System. This diagram shows the simplified interfaces in the RFC systems, where the fuel cell stack box incorporates all fuel-cell chemistry-specific fluidic and thermal hardware. The reactant storage system interfaces are shown with water in blue, hydrogen in yellow, and oxygen in green.

\section{Trade Study Results}

The initial results strongly indicated that, although the base thermodynamic advantages of solid oxide fuel cell technology are encouraging, there are still many details requiring further development to implement solid oxide fuel cell technology for an aerospace application. For all mission locations, PEM fuel cells showed an overall advantage when considered the weighting criteria in Table 2. Each criterion was identified as being maximized or minimized to reflect the most advantageous RFC configuration. A logical comparator evaluated the relative values of each parameter, as shown in Eq. (3). This comparator used applied a positive or negative value of one depending on whether the criterion advantage was based on the value being maximized or minimized.

Normalized Value $=($ LogicalComparator $) *($ WeightFactor $) *($ PEM - SolidOxide $) /[(\mathbf{P E M}+$ SolidOxide $) / 2]$

To avoid perception bias, color-coding was used to note the advantage in the results table, rather than a positive or negative number value. The results for each mission can be seen in Table 3, where PEM advantages are colored in blue and noted by the abbreviation "PEM" while solid oxide advantages are colored in orange and noted by the abbreviate "SOFC". Ties are noted in purple. 
Table 3. RFC Trade Study Performance Metric Results for All Mission Locations.

\begin{tabular}{|c|c|c|c|c|c|c|}
\hline Performance Metric & $\begin{array}{l}\text { Weight } \\
\text { Factor }\end{array}$ & $\begin{array}{c}\text { Parameter } \\
\text { Intent }\end{array}$ & $\begin{array}{c}\text { Mars } \\
\text { Equator }\end{array}$ & $\begin{array}{l}\text { Mars Mid- } \\
\text { Latitude }\end{array}$ & $\begin{array}{c}\text { Moon } \\
\text { Equator }\end{array}$ & $\begin{array}{c}\text { Moon } \\
\text { South Pole }\end{array}$ \\
\hline RFC System Mass & 0.5 & Minimize & $\begin{array}{c}0.19 \\
(\mathrm{PEM})\end{array}$ & $\begin{array}{c}0.16 \\
(\mathrm{PEM})\end{array}$ & $\begin{array}{c}0.08 \\
(\mathrm{PEM})\end{array}$ & $\begin{array}{c}0.14 \\
(\mathrm{PEM})\end{array}$ \\
\hline RFC System Volume & 0.25 & Minimize & $\begin{array}{c}0.01 \\
(\mathrm{PEM})\end{array}$ & $\begin{array}{c}0.01 \\
(\mathrm{PEM})\end{array}$ & $\begin{array}{l}0.0 \\
\text { (tie) }\end{array}$ & $\begin{array}{c}0.0 \\
\text { (tie) }\end{array}$ \\
\hline PV Charge Power Required & 1.0 & Minimize & $\begin{array}{c}0.05 \\
(\mathrm{PEM})\end{array}$ & $\begin{array}{c}0.02 \\
(\mathrm{PEM})\end{array}$ & $\begin{array}{c}0.05 \\
(\mathrm{PEM})\end{array}$ & $\begin{array}{c}0.06 \\
\text { (SOFC) }\end{array}$ \\
\hline Specific Energy & 0.5 & Maximize & $\begin{array}{c}0.10 \\
(\mathrm{PEM})\end{array}$ & $\begin{array}{c}0.08 \\
(\mathrm{PEM})\end{array}$ & $\begin{array}{c}0.01 \\
\text { (SOFC) }\end{array}$ & $\begin{array}{c}0.06 \\
(\mathrm{PEM})\end{array}$ \\
\hline \multicolumn{3}{|c|}{ Weighted Total Value } & $\begin{array}{c}0.36 \\
(\text { PEM) } \\
\end{array}$ & $\begin{array}{c}0.26 \\
(\text { PEM) }\end{array}$ & $\begin{array}{c}0.12 \\
\text { (PEM) }\end{array}$ & $\begin{array}{c}0.13 \\
\text { (PEM) }\end{array}$ \\
\hline
\end{tabular}

For all mission locations, PEM fuel cells emerged as the most advantageous fuel cell technology based on current state-of-the-art data that meets the surface power requirements. For lunar locations, the trade is closer, as the nighttime durations ranging from 73 to over 350 hours make electrolysis the critical RFC component. In particular, the lunar South Pole requires further analysis to investigate the appropriate operating concept for electrolysis. The higher efficiency of solid oxide fuel cells is also more apparent for the lengthy lunar daytime durations. However, the higher system mass, volume, and parasitic power required for the solid oxide fuel cell makes the PEM fuel cell the best overall technology.

To show the relative difference between solid oxide fuel cell-based RFC systems and PEM fuel cell-based RFC systems for each mission location, the total system mass is shown in Figure 7, and total system volume is shown in Figure 8. The PV charge power required is shown in Figure 9. It should be noted that the reactant mass and volume dominate the Moon Equator locations regardless of fuel cell stack chemistry. The system specific energy is depicted in Figure 10. For an explanation of how each metric is calculated, refer to Section II.

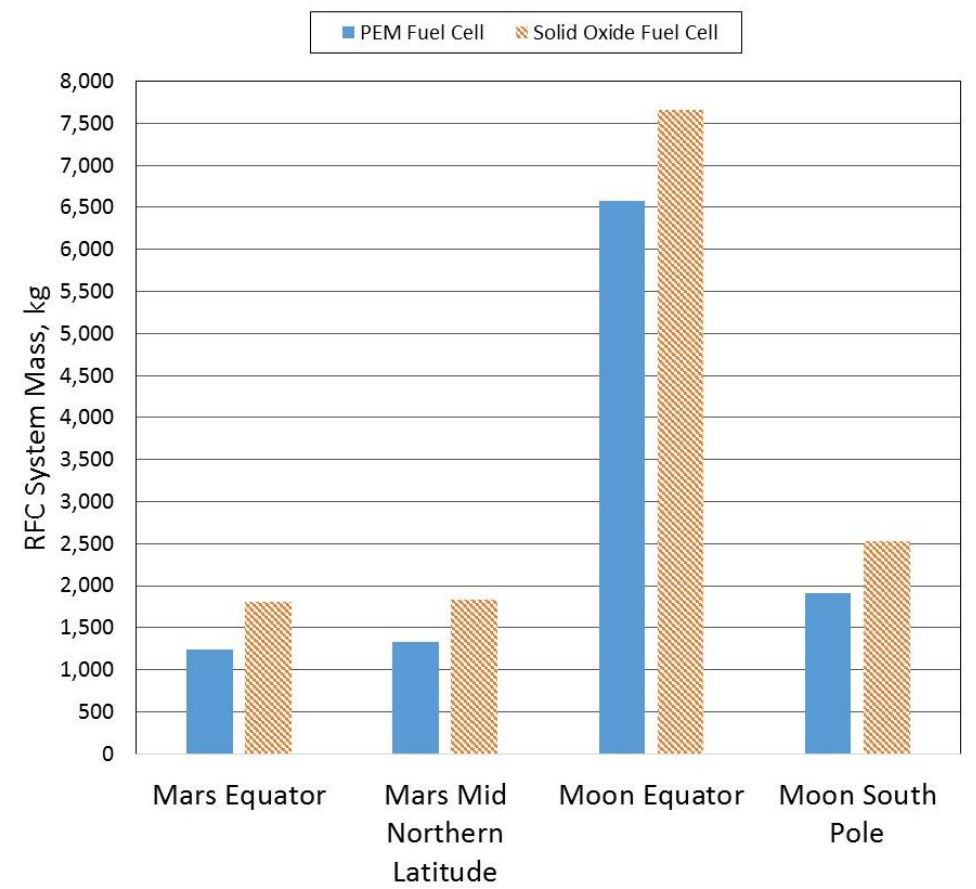

Figure 7. RFC System Mass by Location. PEM fuel cell-based RFC system mass is shown in blue, while solid oxide fuel cell-based RFC system mass is shown in orange. Both fuel cell architectures utilize a PEM electrolysis stack. 


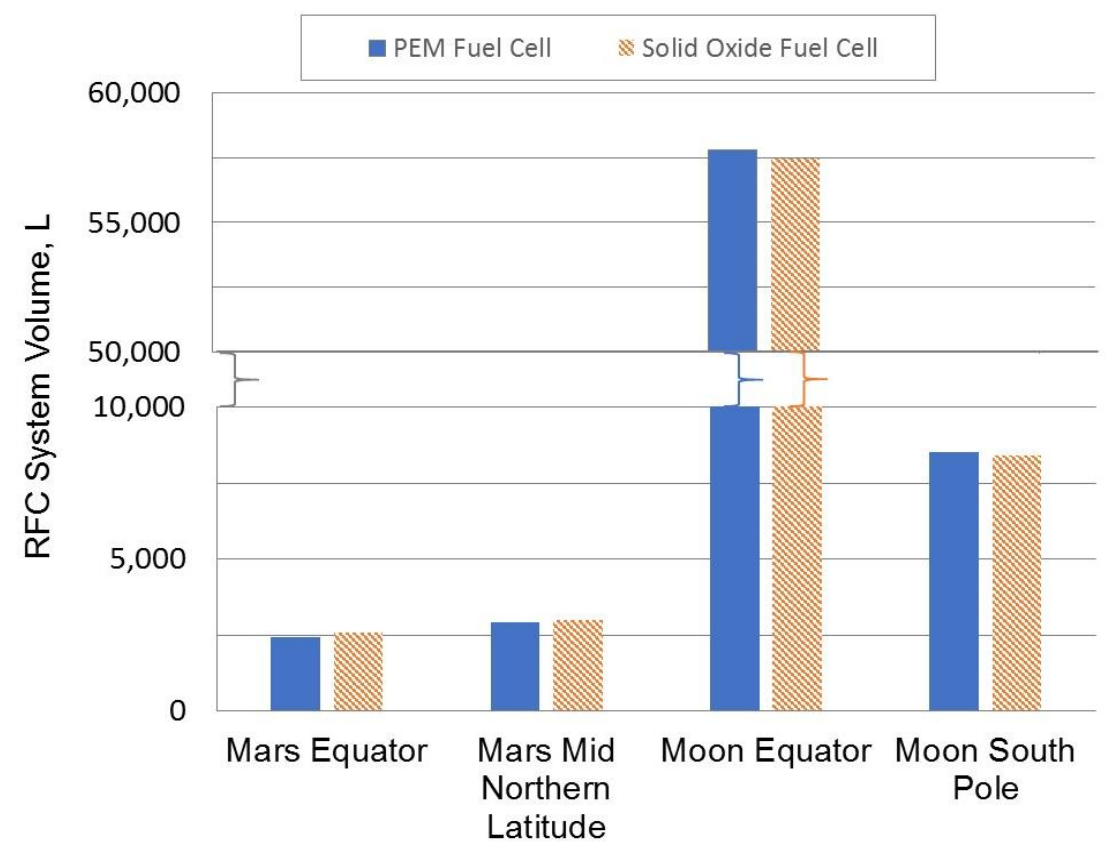

Figure 8. RFC System Volume by Location. PEM fuel cell-based RFC system volume is shown in blue, while solid oxide fuel cell-based RFC system volume is shown in orange. Both fuel cell architectures utilize a PEM electrolysis stack.

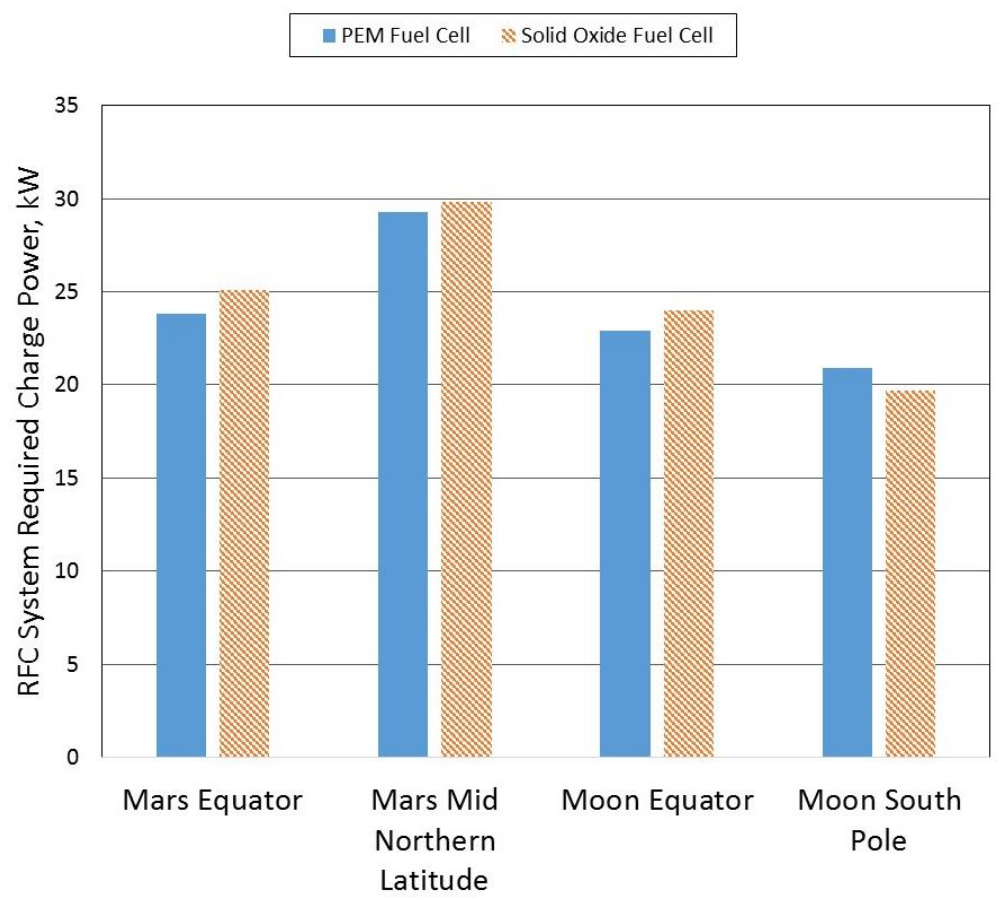

Figure 9. RFC System PV Charge Power by Location. PEM fuel cell-based RFC system PV charge power is shown in blue, while solid oxide fuel cell-based RFC system PV charge power is shown in orange. Both fuel cell architectures utilize a PEM electrolysis stack. PV charge power, or Photovoltaic array charge power, indicates the amount of solar energy needed for RFC operation during the daytime cycle. 


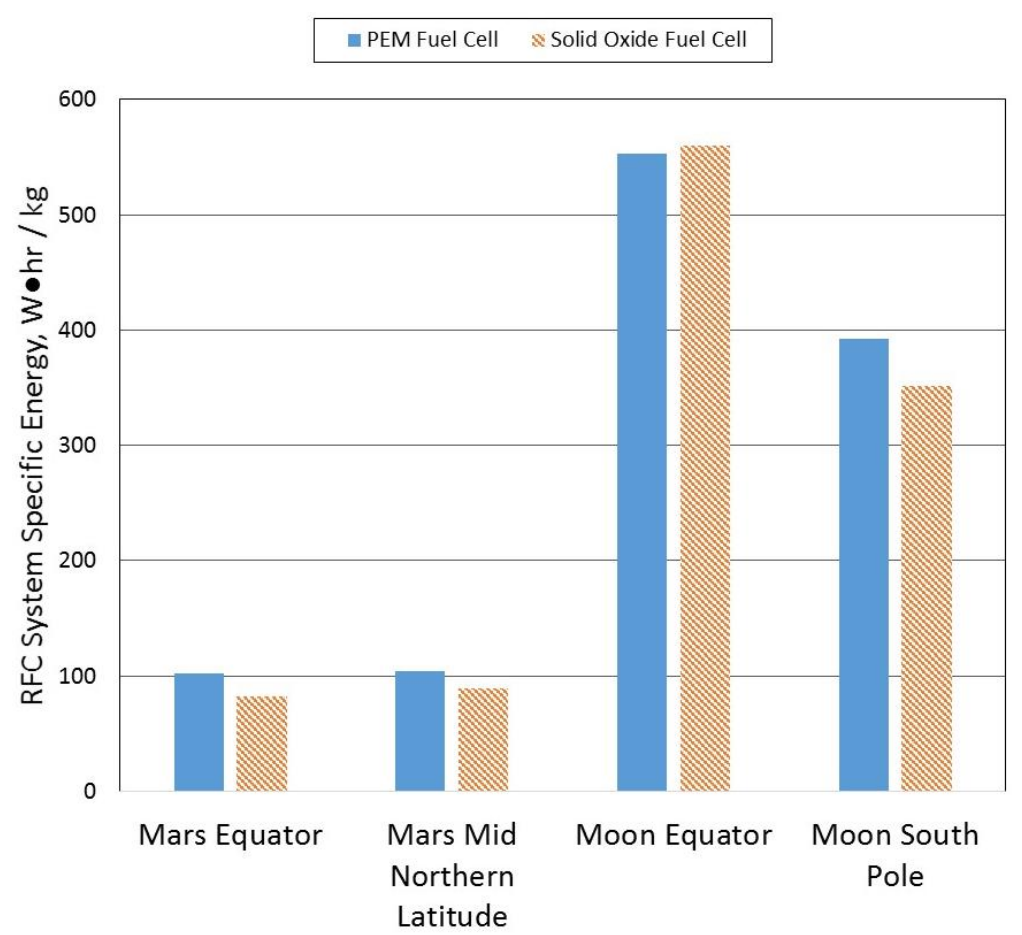

Figure 10. RFC System Specific Energy by Location. PEM fuel cell-based RFC system specific energy is shown in blue, while solid oxide fuel cell-based RFC system specific energy is shown in orange. Both fuel cell architectures utilize a PEM electrolysis stack.

\section{Technology Development Needs}

During the course of the initial trade studies, a number of areas requiring further technology development were identified. For solid oxide fuel cells, particular emphasis on improved thermal management for the stack requires a system-level investigation to optimize the heat exchanger performance. In addition, improved seals for the solid oxide stack would eliminate the need for a second hermetic boundary to mitigate overboard leakage of reactants, which adds significant mass to the system. In general, solid oxide fuel cells are at a lower technology readiness for RFC applications and require further development to become competitive to PEM fuel cells. To this end, the MOXIE flight experiment addresses some of these details on a small scale by electrolyzing carbon dioxide to generate oxygen. With many years of operation in terrestrial and aeronautic applications, PEM fuel cells have a proven pedigree for relevant scale ground operation, but require spaceflight qualification testing as well as lifecycle analysis and testing before a surface mission can be completed.

For integrated system components, a key area for development is a reliable water de-ionization system capable of operating for years without maintenance. The electrolysis water generated must be of a high purity, requiring the development of advanced regenerative deionizers or distillation to remove stray ions and other impurities. Coolant fluid properties and material compatibility is another area for investigation. Current electrochemical stacks require high purity, deionized water coolant, requiring the same deionizing process needed for the product water lines. It is necessary to prevent biological contamination, long-term corrosion, and fluid ionization in the closed-loop liquid water coolant lines. Additionally, optimization of individual components such as reactant storage vessels, pumps, valves, regenerative dryers, and radiators could lower overall system mass and reduce overboard leakage. These components are shared among multiple systems for Mars exploration, from ISRU to space vehicles and landers, and are not specific to RFC applications.

Electrolysis is another area requiring further development. Work is underway to perform a deeper trade study between various electrolyzer types and their impact on RFC performance, including liquid anode feed, liquid cathode feed, and cathode vapor feed. Selection of an optimized electrolyzer could greatly improve integrated system performance and reduce overall system mass through the elimination of some ancillary hardware. Life testing is critical for electrolysis stacks, with a focused effort needed to select the proper materials to meet the lengthy lifecycle requirements for Martian and lunar surface missions. 
This study did not evaluate power management for a surface application, nor did it attempt to address the impact of charge power on a solar array system. Further work is needed to develop a high-efficiency, low-mass PMAD approach for power management between an RFC and solar array to optimize the power provided to the end user. This is critical for mission locations such as the lunar south pole, where the daylight hours with solar power available greatly exceed the nighttime duration. A low-power electrolysis stack could run at minimal input power and slowly generate the reactants required for fuel cell operations over the extended daytime duration, or the electrolysis stack could run at high power for a very short duration prior to supporting an ISRU activity. Further trade studies are required to optimize the electrolysis stack and solar array power output to find a low mass, highefficiency solution.

A low-cost, near-term demonstration of various RFC technologies is possible by splitting technology development into three areas: fuel cells, electrolyzers, and integrated system components. By utilizing a modular, evolvable approach to RFC technology development, such as that shown in Figure 11, current state-of-the-art hardware can be added and updated as it becomes available. For example, an existing, independent fuel cell power system could be connected to the integrated system module, which would interface with a lower-readiness-level electrolysis stack for a relevant scale RFC demonstration. As funding and technology becomes available, the modules are upgraded to become increasingly flight-representative. This would allow additional funding sources and parallel development efforts to be leveraged during the demonstration effort, at a net savings to NASA.

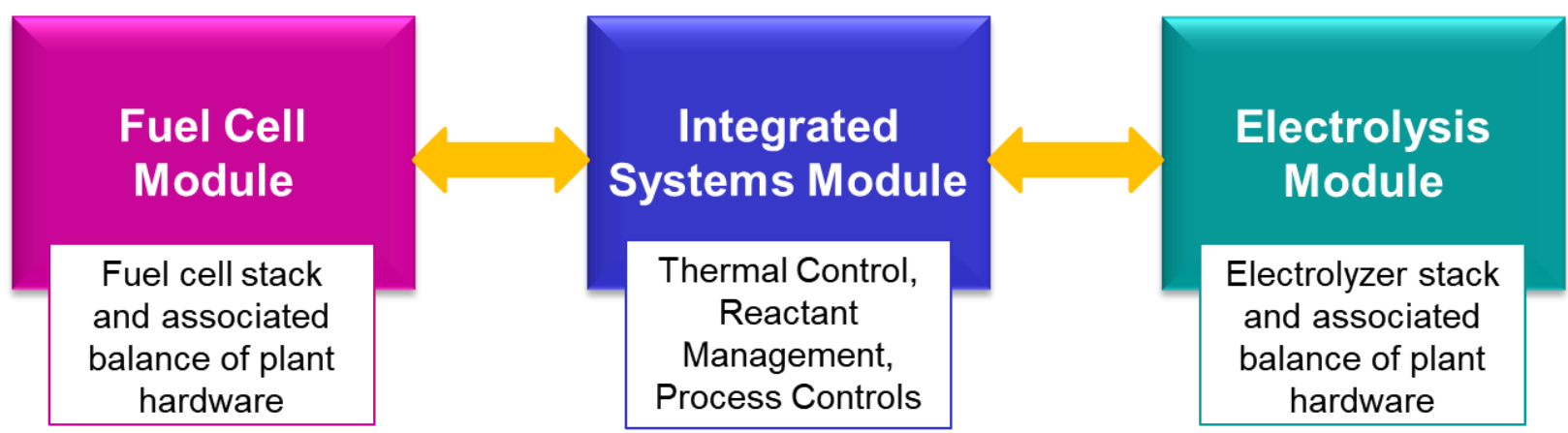

Figure 11. A Modular Evolvable Approach to a RFC Demonstration. By developing each RFC technology area in a modular approach, cost-effective technology development paths can be pursued in parallel or infused later once technology investments are made and hardware becomes available.

\section{Conclusions}

By establishing a common approach towards RFC system development, NASA can begin a cost-effective technology development and implementation strategy that satisfies the requirements of multiple surface locations and missions. The AMPS RFC trade study provides NASA with an option to continue technology development and near-term demonstrations. The project focused on leveraging existing technologies across other NASA and industry users to reduce overall development costs and to promote technology infusion in a variety of technical areas. By developing such an approach for RFC energy storage systems, manned space exploration of non-terrestrial surfaces, such as the Moon and Mars, becomes increasingly viable. For near-term applications and demonstrations, an RFC system architecture based on a PEM fuel cell and PEM electrolysis stack provides the highest advantage to meet surface power requirements across a variety of mission locations. Forward work will focus on defining a detailed RFC system design as well as evaluate potential areas for integration with other surface systems.

\section{Acknowledgments}

The authors would like to acknowledge the Advanced Exploration Systems (AES) project and the AES Modular Power Systems (AMPS) task for the funding support for the trade study effort mentioned in this paper. In particular, the authors would like to thank project managers Karin Bozak and Patrick George, chief technologist James Soeder, and Richard McGinnis. The effort could not have been performed without close collaboration, model sharing, and resource contribution from the Solar Array with Storage (SAWS) project team, led by project manager Frederick Elliot and Space Technology and Mission Directorate principal investigator Lee Mason. Critical members of the SAWS team and valuable contributors to this effort include Thomas Kerslake, Serene Farmer, Robert Green, Kam Mwara, Frank Davies, Aaron Paz, and Koroosh Araghi. 


\section{References}

${ }^{1}$ Rucker, M., et al., "Solar Versus Fission Surface Power for Mars", AIAA SPACE 2016, AIAA SPACE Forum (AIAA-2016-5452)

${ }^{2}$ Drake, B., (ed.), "Human Exploration of Mars: Design Reference Architecture 5.0", Mars Architecture Steering Group, NASA Headquarters, NASA-SP-2009-566, 2009.

${ }^{3}$ Mercer, C., "Battery and Fuel Cell Development Goals for Lunar Surface and Lander", Proceedings of the 2008 Space Power Workshop, Huntington Beach, CA, April 2008.

${ }^{4}$ Nelson, P., "Fuel Cell Systems for First Lunar Outpost - Reactant Storage Options", Argonne National Labs, Department of Energy Contract \#W-31-109-Eng-38, 1996.

${ }^{5}$ Mazanek, D., et al., "Surface Buildup Scenarios and Outpost Architectures for Lunar Exploration", Proceedings of the 2009 IEEE Aerospace Conference, Montana, March 2009, IEEE LF99-8045.

${ }^{6}$ Kerslake, T., “Lunar Surface-to-Surface Power Transfer”, NASA TM 2007-215041, December 2007.

7“NASA’s Plans for Human Exploration Beyond Low Earth Orbit”, Report No. IG-17-017, April 2017.

8“NASA Technology Roadmaps: TA 3: Space Power and Energy Storage”, May 2015.

${ }^{9}$ Hoffman, J., Rapp, D., and Hecht, M., "The Mars Oxygen ISRU Experiment (MOXIE) on the Mars 2020 Rover", AIAA SPACE 2015, AIAA SPACE Forum, AIAA 2015-4561, 2015.

${ }^{10}$ Whitley, R., et al., "Global Exploration Roadmap Derived Concept for Human Exploration of the Moon", Global Space Exploration Conference (GLEX) 2017, Beijing; China, June 2017.

${ }^{11}$ Mazarico, E., et al., "Illumination conditions of the lunar polar regions using LOLA topography", Icarus, Volume 211, Issue 2, February 2011, Pages 1066-1081.

${ }^{12}$ Kerslake, T., Kohout, L., "Solar Electric Power System Analyses for Mars Surface Missions”, NASA TM 1999-209288, 1999.

${ }^{13}$ Landis, G., et al., "Mars Solar Power", Proceedings of the 2nd IECEC, Providence RI, AIAA 2004-5555, 2004.

${ }^{14}$ Barbir, F., "PEM Fuel Cells: Theory and Practice," Elsevier Publishing, 2005, ISBN-10: 0120781425, ISBN13: 9780120781423

${ }^{15}$ LeRoy, R., Bowen, C., “The Thermodynamics of Aqueous Water Electrolysis”, Journal of Electrochem. Soc., Vol 127, No. 9, pp 1954-1962, 1980.

${ }^{16}$ Millet, P., et al., "Electrochemical performances of PEM water electrolysis cells and perspectives", International Journal of Hydrogen Energy 36, pages 4134-4142, 2011.

${ }^{17}$ Onda, K., et al., "Prediction of production power for high-pressure hydrogen by high-pressure water electrolysis", Journal of Power Sources 132, pages 64-70, 2004.

${ }^{18}$ Laoun, B., "Thermodynamics aspect of high pressure hydrogen production by water electrolysis", Revue des Energies Renouvelables, Vol. 10, №3, pages $435-444,2007$. 
${ }^{19}$ Sakai, T., "Gas Diffusion in the Dried and Hydrated Nafions”, Journal of Electrochem. Soc., Volume 133, Issue 1, Pages 88-92, 1986

${ }^{20}$ Greenway, S., Fox, E., Ekechukwu, A., "Proton exchange membrane (PEM) electrolyzer operation under anode liquid and cathode vapor feed configurations", International Journal of Hydrogen Energy 34, pages 66036608, 2009

${ }^{21}$ Narayanan, S., et al., "Dual-Feed Balanced High-Pressure Electrolysis of Water in a Lightweight Polymer Electrolyte Membrane Stack”, Journal of the Electrochemical Society, 158, B1348-B1357, 2011

${ }^{22}$ Fowler, M. "Degradation and Reliability Analysis of PEM Fuel Cell Stacks", University of Waterloo Department of Chemical Engineering, < http://chemeng.uwaterloo.ca/mfowler/reliability.pdf>

${ }^{23}$ Gilligan et al., "Modeling Thermal Control Systems for Extraterrestrial Regenerative Fuel Cells", Presented at NASA Thermal and Fluids Analysis Workshop 2017, August 2017.

${ }^{24}$ Metcalf, K., "Power Management and Distribution (PMAD) Model Development”, NASA/CR-2011-217268, 2011 